\title{
SIMULAÇÃO COMPUTACIONAL E MEDIÇÕES IN LOCO: UM ESTUDO DO DESEMPENHO HIGROTÉRMICO EM UM EDIFÍCIO ALTO EM BRASÍLIA
}

\author{
DANTAS, ANDRÉ LUÍS DE FARIA \\ Arquiteto e Urbanista \\ Universidade de Brasília \\ Distrito Federal; Brasil \\ andreldants@gmail.com
}

\author{
ZANONI, VANDA ALICE GARCIA \\ Engenheira Civil \\ Universidade de Brasília \\ Distrito Federal; Brasil \\ vandazanoni@unb.br
}

\section{RESUMO}

As condições de exposição ao clima afetam a durabilidade dos sistemas construtivos de um edifício e seu desempenho higrotérmico. Ainda são escassos os trabalhos que buscam avaliar a sensibilidade dos resultados às condições climáticas previstas, como base para explorar projetos de construção e seleção de materiais a partir da perspectiva da resiliência climática. Entender a melhor forma de aumentar a resiliência das envoltórias a climas futuros exige uma análise mais abrangente das condições de umidade e temperatura dos materiais ao longo do tempo. Essa pesquisa buscou medir o comportamento higrotérmico de uma fachada de um edifício alto em parede de alvenaria de blocos de concreto na cidade de Brasília. Para medição da chuva dirigida foi utilizada uma bandeja coletora posicionada na fachada Leste da edificação. Por meio de medições in loco foram coletados dados de umidade e temperatura utilizando sensores de umidade e temperatura do tipo AM2302 DHT22, posicionados na parte interna e externa da parede da fachada Leste, conectados a um microcontrolador Arduino Uno que registrou os dados a cada 10 minutos. Para análise de sensibilidade e compreensão dos fenômenos higrotérmicos atuantes no sistema construtivo, foram feitas simulações computacionais no programa WUFI Pro. Os resultados de umidade, temperatura e chuva dirigida obtidos nas medições em campo foram comparados com os resultados obtidos na simulação computacional, permitindo o estudo do desempenho higrotérmico por meio da análise dos resultados do transporte de calor e massa do sistema de fachada.

Palavras-chave: simulação, medições, desempenho higrotérmico, resiliência climática, chuva dirigida.

\begin{abstract}
Weather exposure conditions can affect the durability and hygrothermal performance of building systems. There are still few studies that seek to evaluate the sensitivity of the results to the predicted climatic conditions, as a base for exploring construction projects and the selection of materials from the perspective of climate resilience. Understanding the best way to increase the resilience of envelope to future climates requires a more comprehensive analysis of the humidity and temperature conditions of materials over time. This work aimed to quantify the driven rain and its effects on the hygrothermal behavior of a facade of a tall building in a concrete block masonry wall in the city of Brasilia. To measure the driven rain collection trays were used, positioned on the north and east facades of the building. Humidity and temperature data were collected using on-site measurements AM2302 DHT22 temperature and humidity sensors, positioned inside and outside the East facade wall, connected to an Arduino Uno microcontroller that recorded the data every 10 minutes. For sensitivity analysis and comprehension of the hygrothermal phenomena acting in the constructive system, computer simulations were performed in the WUFI Pro program. The results of humidity, temperature and driven rain obtained in the field measurements were compared with the results obtained in the computer simulation, allowing the understanding of the hygrothermal performance of the facade system and the analysis of heat and mass transport through the façade wall in different exposure situations.
\end{abstract}

Keywords: simulation, measurements, hygrothermal performance, climate resilience, driven rain. 


\section{INTRODUÇÃO}

Um dos diversos sistemas construtivos que utilizam o concreto é a alvenaria em blocos de concreto, amplamente adotada no Brasil e no mundo, graças ao seu desempenho térmico e resistência física, além de consumir menos energia nos processos produtivos do que os blocos cerâmicos (DE COL DÍAZ et al, 2013). Ao mesmo tempo que são desenvolvidas melhorias nos sistemas construtivos, surgem novas demandas relacionadas ao controle dos gradientes de umidade nos diferentes componentes das edificações e seu impacto no consumo de energia, no conforto e na saúde dos ocupantes, na durabilidade e no ciclo de vida dos materiais (BUI; LABAT; LORENTE, 2019). Os construtores precisam estar cada vez mais atentos aos desafios impostos para a construção de edificações mais resilientes.

O concreto é o material de construção mais utilizado no mundo, para todos os tipos de edificações, grandes ou pequenas, em diferentes composições e sistemas construtivos. Apesar de ser amplamente estudado no que diz respeito à suas propriedades mecânicas, composições e processos de cura, pouco se sabe sobre as suas propriedades de transporte de umidade ao longo do tempo (KÜNZEL; HOLM; KRUS, 2008). A norma brasileira NBR 15575-1 (ABNT, 2013) aborda questões referentes à durabilidade e ao desempenho dos sistemas construtivos de edificações residenciais. Apesar de apresentar requisitos de desempenho térmico, não existem exigências quanto ao comportamento higrotérmico dos sistemas construtivos na realidade brasileira.

Sabe-se que a chuva dirigida é uma das principais fontes de umidade das edificações. Sua ação pode afetar a durabilidade e o desempenho dos sistemas construtivos de um edifício, em especial as fachadas, conforme suas condições de exposição ao meio ambiente. O potencial danoso da chuva dirigida pode causar problemas que vão desde a penetração de chuva, degradação química e biológica dos componentes construtivos, manchas por eflorescência, surgimento de fissuras geradas pelas variações térmicas, entre outros (BLOCKEN; DEROME; CARMELIET, 2013).

A simulação computacional pode contribuir para compreensão das condicionantes climáticas que influenciam na vida útil dos sistemas construtivos, possibilitando a criação de modelos e avançando no entendimento do comportamento higrotérmico. Outro passo para compreender os danos que resultam da ação da umidade e da temperatura nas construções é o monitoramento em campo das condições internas e externas de umidade e temperatura (COELHO; SILVA; HENRIQUES, 2018). Quando o método de pesquisa permite associar os procedimentos de campo com as simulações, os dados coletados proporcionam maior sensibilidade e confiabilidade no entendimento dos fenômenos.

Neste contexto, esse estudo tem o objetivo de estudar a ação da umidade e temperatura, internamente e externamente, em uma edificação de alvenaria de alvenaria de blocos de concreto localizada em Brasília- DF, por meio de simulações computacionais e medições em campo realizadas durante o mês de fevereiro e março de 2019, buscando a compreensão do comportamento higrotérmico do sistema construtivo.

\section{MÉTODO}

O estudo foi desenvolvido por meio das seguintes etapas: revisão bibliográfica, coleta de dados por meio das medições em campo utilizando sensores de umidade e temperatura e coletores de chuva, simulação computacional higrotérmica e análises de dados coletados.

O software de simulação higrotérmica WUFI Pro 6.2 (Wärme- Und Feuchtetransport Instationär - Transient Heat and Moisture Transport) foi utilizado para fazer a simulação computacional, utilizando arquivos climáticos em formato TMY (Typical Meteorological Year) com dados medidos pelo INMET (Instituto Nacional de Meteorologia). Os arquivos climáticos utilizados nessa pesquisa estão disponíveis no sítio eletrônico do LabEEE (Laboratório de Eficiência Energética em Edificações) nas versões 2016 e 2018. A simulação visou calcular as condições de exposição aos agentes climáticos em uma determinada localidade durante um ano climático típico.

As medições em campo foram realizadas em um edifício em altura, de alvenaria de bloco de concreto, localizada na cidade de Brasília-DF, na Zona Bioclimática 4 (Figura 1). As medições ocorreram na parte mais alta do edifício, com mais de 20 metros de altura, especificamente em um apartamento no sexto andar. Durante as medições, o apartamento encontrava-se em uso regular, habitado por 4 pessoas. As renovações de ar aconteciam tanto pelas janelas quanto por aparelhos de ar-condicionado. Foram medidas quatro variáveis: umidade relativa do ar na superfície externa, umidade relativa do ar na superfície interna, temperatura na superfície externa e temperatura na superfície interna. As medições foram realizadas por meio de dois sensores DTH22 posicionados na face interna e externa da parede de alvenaria da 
fachada Leste (Figura 2). Os sensores foram conectados a um microcontrolador Arduino Uno que armazena e registra os dados a cada 10 minutos.

A)

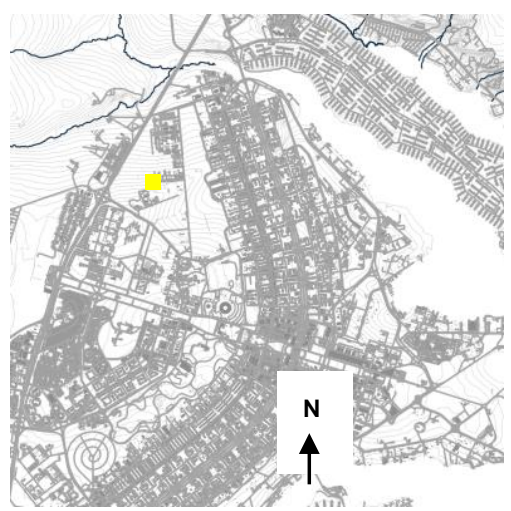

B)

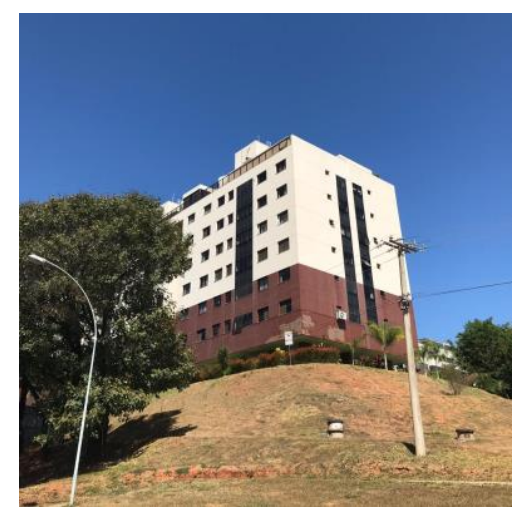

Figura 1 - Edifício em altura: A) Localização em Brasília-DF; B) Edifício Renato Russo Fonte: Autores

A)

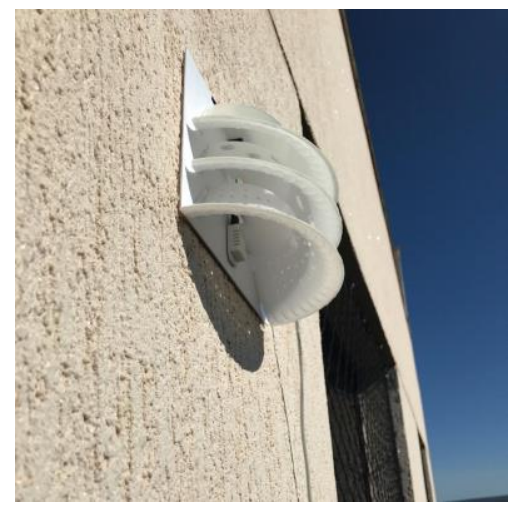

B)

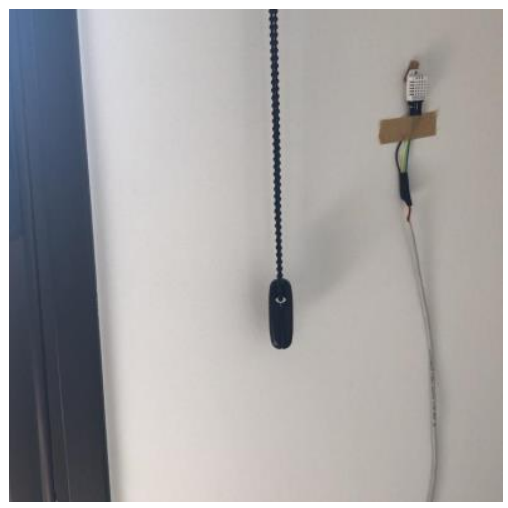

Figura 2 - Sensores DTH22- A) Posição do sensor na face externa da parede; B) Posição do sensor na face interna da parede. Fonte: Autores

Foram coletados, também, dados de chuva dirigida utilizando uma bandeja coletora fixada na fachada Leste do edifício e conectada a uma mangueira, que conduz a água incidente na bandeja para um reservatório (Figura 3). A bandeja coletora possui uma área equivalente a $1 / 16 \mathrm{de} 1 \mathrm{~m}^{2}$, ou seja, $625 \mathrm{~cm}^{2}$ e o reservatório possui capacidade para mais de 2 litros de água (ZANONI et al., 2018).

A)

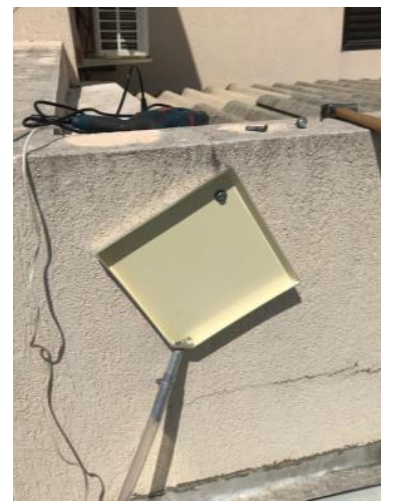

B)

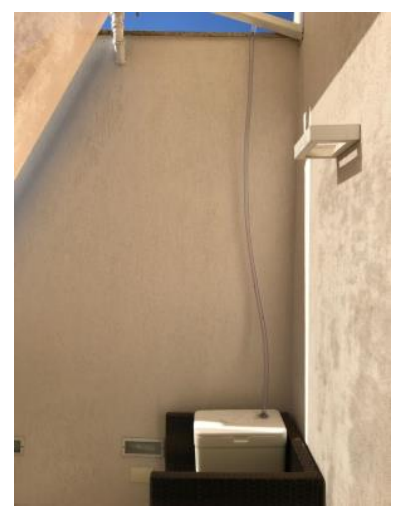

Figura 3 - Bandejas Coletoras- A) Posição da bandeja coletora; B) Posição do reservatório abaixo da bandeja. Fonte: Autores 
O cruzamento das informações obtidas por meio dos dados coletados nas simulações e nas medições em campo pode ser um eficiente método de calibração e validação dos métodos de pesquisa in loco. Esse método permite uma análise de sensibilidade do que fora medido em campo com o arquivo climático, que apresenta valores horários para os meses de fevereiro e março. No sistema de vedação vertical do edifício em questão foi utilizada uma parede de alvenaria de bloco de concreto de $9 \mathrm{~cm}$ de espessura e argamassa de revestimento em ambas as faces, com $2 \mathrm{~cm}$ de espessura (Figura 4).

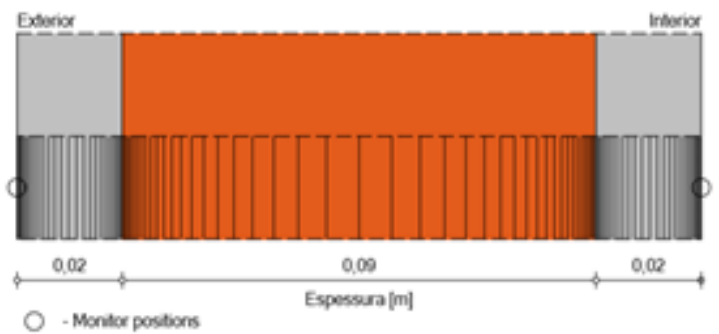

$\begin{array}{ll}\text { Argamassa de Revestimento } & 2 \mathrm{~cm} \\ \text { Bloco de Concreto } & 9 \mathrm{~cm} \\ \text { Argamassa de Revestimento } & 2 \mathrm{~cm}\end{array}$

Figura 4 - Caracterização do sistema construtivo simulado. Fonte: WUFI, adaptado pelos autores.

Outro aspecto importante para a simulação é a altura do edifício, que no caso dessa pesquisa é classificada como edifício alto com mais de 20 metros de altura. Quanto maior a altura do edifício, maior será a velocidade do vento e a incidência de chuva dirigida. Em Brasília, o diagrama de chuva dirigida (Figura 5) indica o comportamento anual da chuva incidente, predominante nas fachadas Norte e Noroeste.

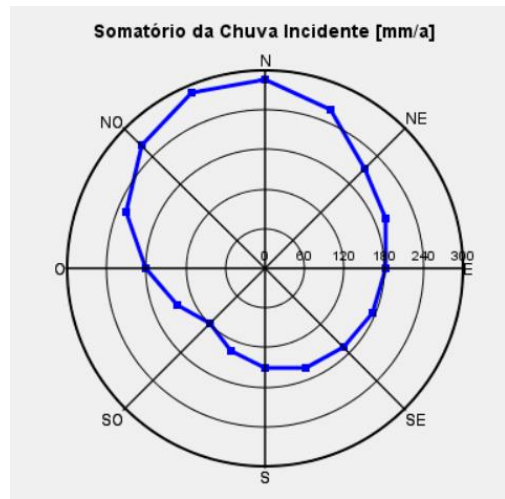

Figura 5 - Diagrama do somatório anual da chuva dirigida na cidade de Brasília.

Fonte: WUFI, adaptado pelos autores.

A fachada Norte é aquela que concentra os maiores índices de chuva dirigida nos meses de fevereiro e março. No entanto, nesta pesquisa de campo, foram coletados dados da fachada Leste, pois esta era a única disponível para receber os sensores e as bandejas coletoras.

\section{RESULTADOS}

Os valores obtidos na simulação para o mês de fevereiro e março estão expostos nas Figuras 6 e 7. Os valores simulados de temperatura superficial exterior atingiram valores mínimos e máximos de $16,34{ }^{\circ} \mathrm{C}$ e de $38,11^{\circ} \mathrm{C}$, respectivamente. Os valores de umidade relativa da superfície exterior variaram entre $20 \%$ e 99,9\%. Na superfície interna, os valores de temperatura variaram de $20,38^{\circ} \mathrm{C}$ a $26,75^{\circ} \mathrm{C}$, enquanto a umidade superficial interna variou de $54,98 \%$ a $93,81 \%$.

Na simulação, percebeu-se que os valores de umidade relativa superficial interna aumentaram à medida que os valores de temperatura da superfície interna diminuíram, característico do período do ano em questão. 

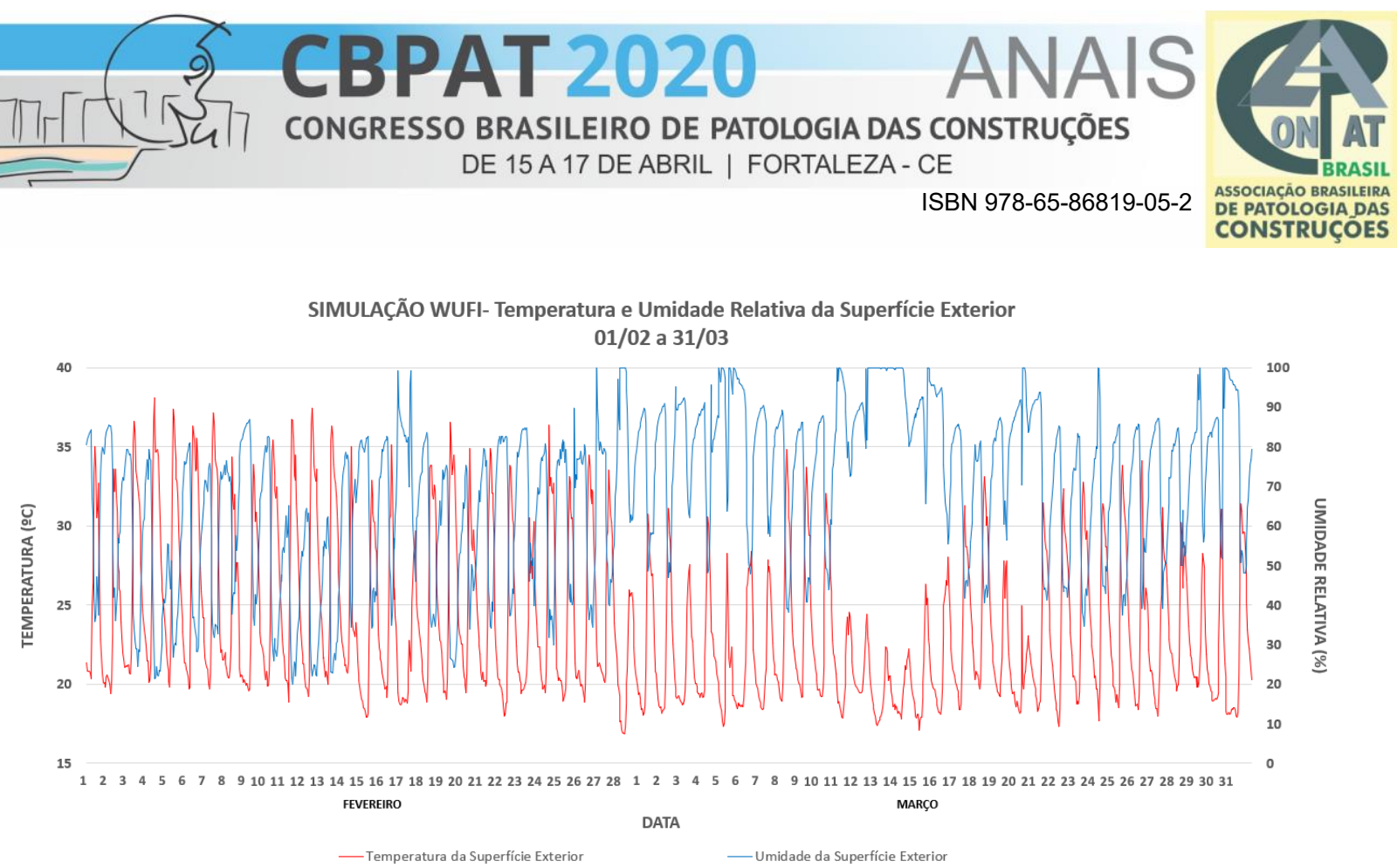

Figura 6 - Valores de simulação desenvolvida no software WUFI Pro para o ambiente externo. Fonte: Autores.

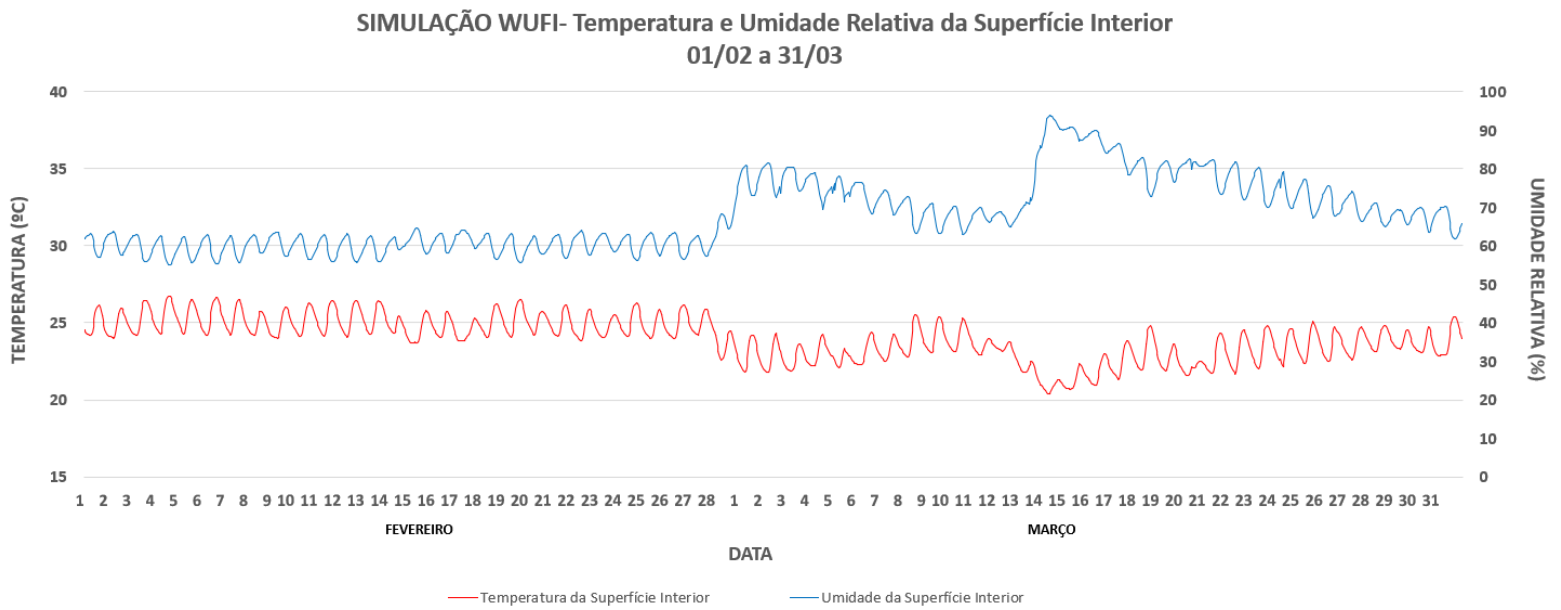

Figura 7 - Valores de simulação desenvolvida no software WUFI Pro para o ambiente interno.

Fonte: Autores.

Os valores de chuva dirigida obtidos na coleta durante os meses da pesquisa de campo estão expostos na Tabela 1 .

Tabela 1 - Valores de Chuva Dirigida

\begin{tabular}{|c|c|c|c|}
\hline Data & $\begin{array}{l}\text { Fachada Leste } \\
\text { Volume }(\mathrm{mL})\end{array}$ & $\begin{array}{l}\text { Fachada Leste } \\
\text { Volume Total (L) }\end{array}$ & $\begin{array}{c}\text { Volume/ Área } \\
\left(\mathrm{L} / \mathrm{m}^{2}\right)\end{array}$ \\
\hline $26 / 01 / 2019$ & 10 & \multirow{8}{*}{0,64} & \multirow{8}{*}{10,24} \\
\hline $05 / 02 / 2019$ & 22 & & \\
\hline $06 / 02 / 2019$ & 196 & & \\
\hline $12 / 02 / 2019$ & 68 & & \\
\hline $19 / 02 / 2019$ & 146 & & \\
\hline $23 / 02 / 2019$ & 52 & & \\
\hline $25 / 02 / 2019$ & 92 & & \\
\hline $27 / 02 / 2019$ & 54 & & \\
\hline $03 / 03 / 2019$ & 490 & \multirow{4}{*}{0,64} & \multirow{4}{*}{10,24} \\
\hline 06/03/2019 & 24 & & \\
\hline $13 / 03 / 2019$ & 116 & & \\
\hline $21 / 03 / 2019$ & 10 & & \\
\hline
\end{tabular}

Fonte: Autores. 
Os valores obtidos na coleta da chuva dirigida indicam que a incidência de chuva foi de $10,241 / \mathrm{m}^{2}$ e que ambos os meses tiveram exatamente a mesma quantidade de chuva, apesar da melhor distribuição em fevereiro. Entretanto, os valores estão abaixo dos valores encontrados no arquivo climático que previa respectivamente $29,401 / \mathrm{m}^{2}$ e 32,33 1// ${ }^{2}$ para fevereiro e março.

Os valores obtidos nas medições em campo de temperatura estão expostos nas Figura 8, e os de umidade relativa estão expostos nas Figura 9.

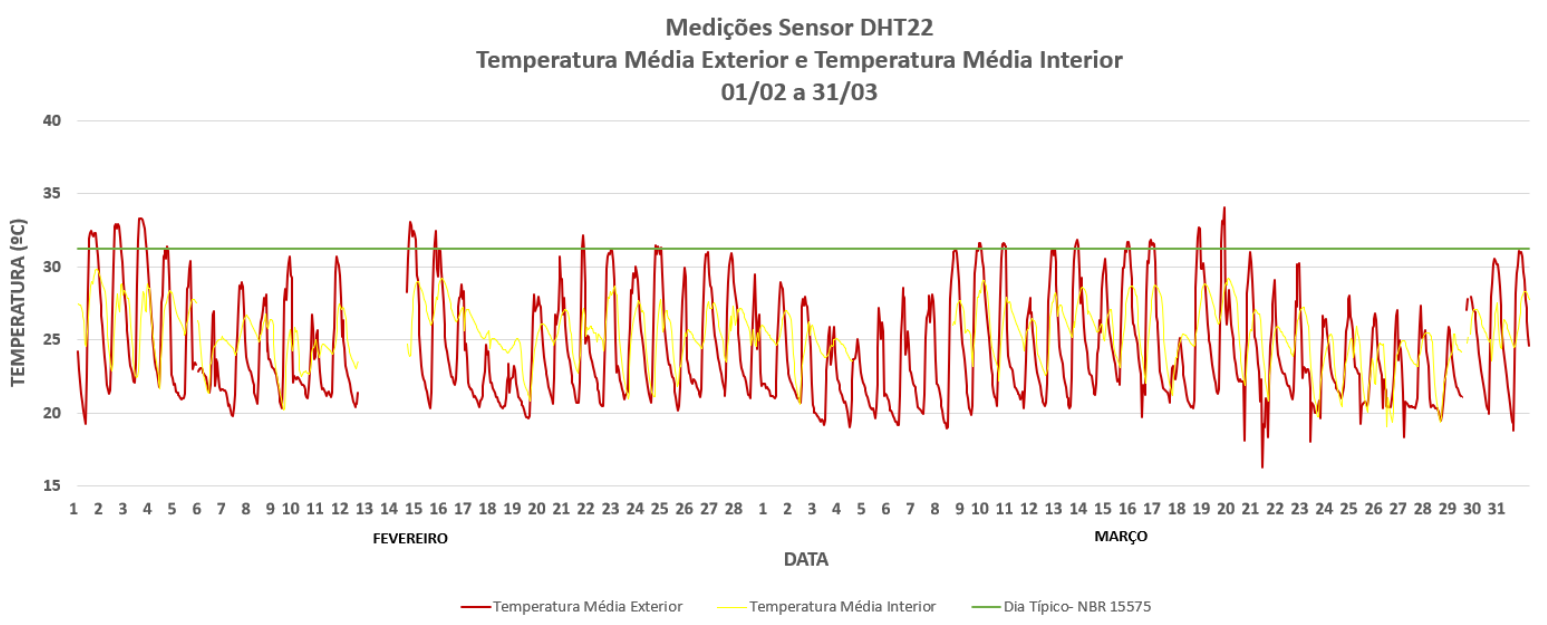

Figura 8 - Temperatura Interna e Externa e Limite Normativo

Fonte: Autores.

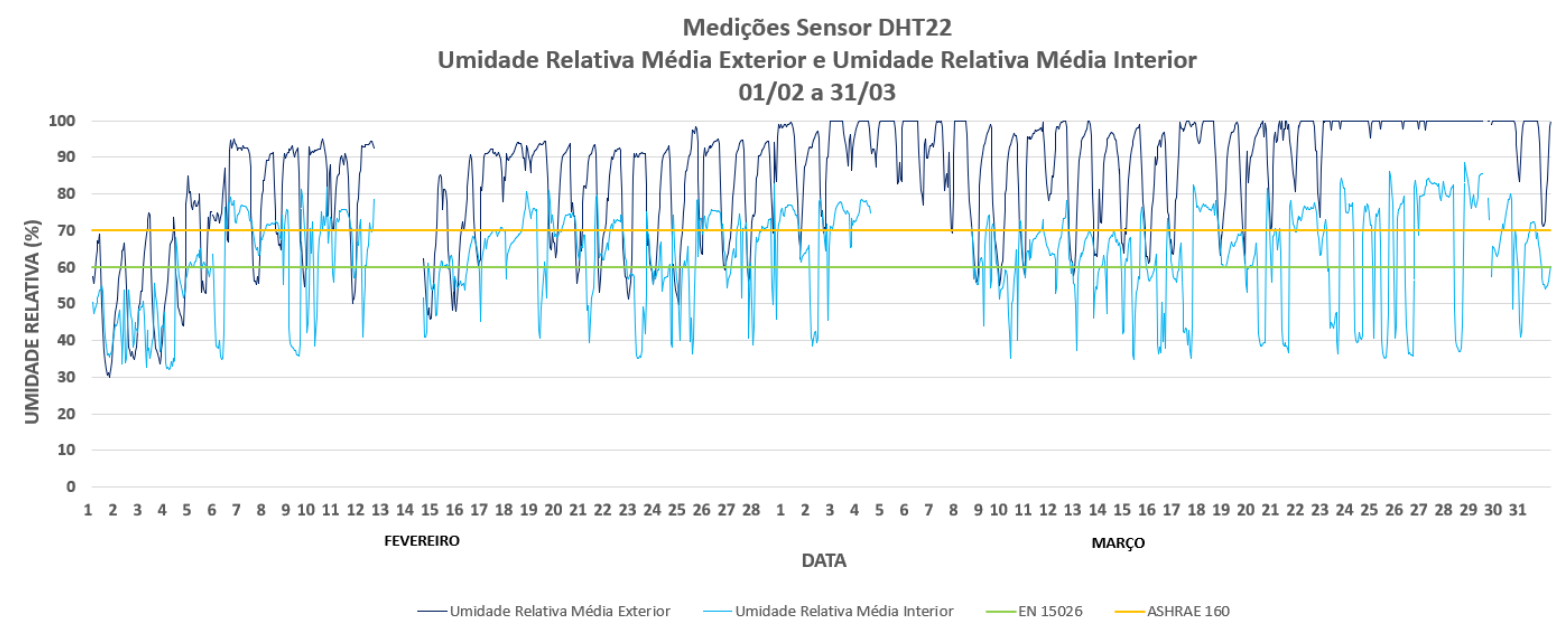

Figura 9 - Umidade Relativa Interna e Externa e Limites Normativos Fonte: Autores.

Os valores de temperatura medidos externamente variaram entre $16,3^{\circ} \mathrm{C}$ e $34,05^{\circ} \mathrm{C}$, enquanto a umidade relativa obteve valores no intervalo entre $29,9 \%$ e $99,9 \%$, estando próximos dos valores obtidos na simulação. Internamente, a temperatura variou entre $19,4^{\circ} \mathrm{C}$ e $29,81^{\circ} \mathrm{C}$ e a umidade relativa variou entre $32,25 \%$ e $88,56 \%$.

A Norma de Desempenho (NBR 15575-1) estabelece que para a Zona Bioclimática 4 a temperatura interna deve ser sempre menor ou igual à temperatura externa e que o dia típico de verão em Brasília atinge temperatura máxima de $31,2^{\circ} \mathrm{C}$. Pôde-se observar que em grande parte do período analisado, o sistema construtivo satisfez a exigência normativa, além de que a temperatura interna em nenhum momento ultrapassou o limite do dia típico de verão. 
A NBR 15575 não estabelece valores de referência para a umidade relativa interna. As normas ASHRAE 160 e EM 15026, estabelecem os limites de $70 \%$ e 60\%, respectivamente. Observa-se na Figura 9 que, em ambos os casos, a umidade relativa superficial medida ultrapassou os limites estipulados, entretanto, a umidade relativa interna obteve valores próximos aos valores da ASHRAE 160. Nota-se que os picos de umidade relativa interior coincidem com os de umidade relativa exterior. Isso indica que o sistema construtivo da envoltória, à medida que recebe a chuva dirigida, permite a entrada de umidade para o interior da edificação.

\section{CONCLUSÕES}

Nessa pesquisa de Iniciação Científica foram realizadas simulações e medições em campo para avaliar o comportamento higrotérmico para os meses de fevereiro e março da fachada Leste de um edifício em altura de blocos de concreto revestidos com argamassa, localizada em Brasília- DF.

As medições em campo realizadas no ambiente externo obtiveram valores próximos aos simulados. No ambiente interno, foram percebidas diferenças maiores entre os valores medidos e simulados. As diferenças entre os valores simulados e medidos internamente sugerem que a parede do edifício permite um fluxo de umidade para o interior da edificação maior do que o previsto na simulação. Os valores de umidade relativa interna variaram significativamente em relação aos limites estabelecidos nas normas internacionais. Os valores de temperatura interna medidos em campo indicam que a temperatura em nenhum momento ultrapassou os limites recomendados pelo dia típico de verão das normas brasileiras.

A pesquisa realizada mostra que o monitoramento do desempenho higrotérmico pode ser facilmente realizado e as medições em campo associadas às simulações computacionais permitem que as avaliações do comportamento dos componentes que compõem os sistemas melhorem as especificações técnicas, tornando os sistemas construtivos mais resilientes às condições de exposição geradas pelas mudanças climáticas.

\section{AGRADECIMENTOS}

Á Universidade de Brasília, no âmbito do Programa de Iniciação Científica (PROIC- UnB) e ao grupo de pesquisa de Simulação Computacional no Ambiente Construído (SICAC).

\section{REFERÊNCIAS}

AMERICAN SOCIETY OF HEATING, REFRIGERATING AND AIR-CONDITIONING ENGINEERS. ASHRAE 160 Criteria for Moisture-Control Design Analysis in Buildings. Atlanta. 2016.

ASSOCIAÇÃO BRASILEIRA DE NORMAS TÉCNICAS. NBR 15.575-1 Edificações habitacionais - Desempenho - Parte 1: Requisitos gerais. Rio de Janeiro, 2013.

BUI, R.; LABAT, M.; LORENTE, S. Impact of the occupancy scenario on the hygrothermal performance of a room. Building and Environment. v. 160. p, 1-12. 2019.

CONSELHO DE ARQUITETURA E URBANISMO DO BRASIL - CAU/BR. Pesquisa CAU/BR Datafolha. 2015. Disponível em: 〈https://www.caubr.gov.br/pesquisa2015/〉. Acesso: 10 out. 2018.

BLOCKEN, B; DEROME, D; CARMELIET, J. Rainwater runoff from building facades: A review. Building and Environment. v.60. p. 339-361. 2013.

COELHO, G.; SILVA, H. E.; HENRIQUES, F. Calibrated hygrothermal simulation models for historical buildings. Building and Environment. v.142. p. 439-450. Set. 2018.

DE COL DÍAZ, J. et al. Hygrothermal study of lightweight concrete hollow bricks: A new proposed experimental-numerical method. Energy and Buildings. v.70. p-194-206. 2014. 


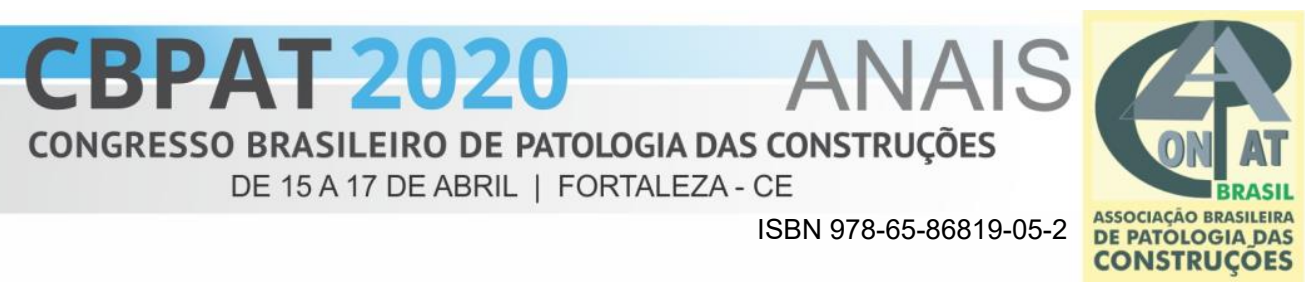

EUROPEAN STANDARDS. German Institute for Standardization. DIN EN 15026 Hygrothermal performance of building components and building elements - Assessment of moisture transfer by numerical simulation. Berlin. p. 26. 2007.

KÜNZEL, H,; HOLM, A,; KRUS, M. Hygrothermal properties and behavior of concrete. WTA- Almanach. P. 161181. 2008.

ZANONI, V.A.G.; SANCHEZ, J.M. M.; BAUER, E. Métodos para quantificação de chuva dirigida incidente nas fachadas das edificações. PARC Pesquisa em Arquitetura e Construção, Campinas, SP, v. 9, n. 2, p. 122-132, jun. 2018.

ZANONI, V.A.G. Influência dos agentes climáticos de degradação no comportamento higrotérmico de fachadas em Brasília. 2015. 313 f. Tese de doutorado em Arquitetura e Urbanismo. PPG FAU-UnB. Universidade de Brasília, Brasília. 